Full-text Available Online at www.ajol.info and www.bioline.org.br/ja
J. Appl. Sci. Environ. Manage. Dec., 2015

Vol. 19 (4) 761 - 764

\title{
Toxic Potential of Carcinogenic Polycyclic Aromatic Hydrocarbons (cPAHs) and Heavy Metal in Crude Oil from Gokana Area, Rivers State, Nigeria
}

\author{
${ }^{* 1}$ IWUOHA, G; ${ }^{1}$ ORUBITE, O; ${ }^{1}$ OKITE I
}

\author{
${ }^{I}$ Department of Pure and Industrial Chemistry, Faculty of Sciences, University of Port Harcourt
}

\begin{abstract}
This article is focused on ascertaining the toxic potentials of heavy metals and the levels of PAHs and cPAHs in crude oil samples from Gokana area and using the data to determine the carcinogenicity (toxicity) of the cPAHs in the crude oil. All the cPAHs namely; benzo (a) pyrene, benzo (a) Anthracene, benzo (b) Fluoranthene, chrysene, benzo (k) fluoranthene, dibenzo $(\mathrm{a}, \mathrm{h})$ perylene and indeno $(1,2,3-\mathrm{cd})$ pyrene were detected at various concentration in $\mathrm{mg} / \mathrm{l}$ as 1597.88, 46.97, 4219.99, 1498.04, 1220.41,831.82 and 1106.20 respectively. The total concentration of cPAHs is $10,474.34 \mathrm{mg} / \mathrm{l}$ which represent $41.83 \%$ of the total PAHs (tPAHs) in the crude oil sample. Using BaP as baseline standard $(0.0007 \mathrm{mg} / \mathrm{l})$ to correlate the (toxicity) carcinogenicity of the cPAHs, we found out that the crude oil sample is many thousands of folds significantly and exceedingly (toxic) carcinogenic. The order of concentration of heavy metal $(\mathrm{Fe}>\mathrm{Ni}>\mathrm{Cr}>\mathrm{Cu}>\mathrm{Cd}=\mathrm{Pb}=\mathrm{Zn})$ in the crude oil sample did not reflect their actual toxic potential as only nickel and chromium exceeded the maximum effluents limits. Considerable caution should be applied in exploration, exposure and distribution of the crude oil through protected and well maintained pipelines to avoid the possible release of PAHs as well as nickel and chromium toxicity to soil, water and inhabitants of Gokana area. ( ) JASEM
\end{abstract}

http://dx.doi.org/10.4314/jasem.v19i4.24

\section{KEYWORDS: carcinogenicity, toxicity, crude oil, heavy metal, cPAHs}

\section{INTRODUCTION}

Crude oil is a known major source of Polycyclic Aromatic Hydrocarbons (PAHs), which contain potentially carcinogenic and other toxic substances that persist in the environment with their attendant health consequences (U.S.E.P.A., 1993a). Exploration and production activities of petroleum in the Niger delta, Nigeria has led to the accidental discharges of crude oil to the environment which adversely affect air, water, sediment and soil directly and indirectly leading to loss of biodiversity, forest degradation, acidic rain and despoilment of aquatic biota (Osuji and Uwakwe, 2006; Osuji et al., 2007).

The inhabitants of the crude oil province of Niger delta are exposed to crude oil directly or indirectly through soil, air and water. There are so many reports on crude oil spillage within the Niger Delta which has attracted local and international attention (Osuji and Uwakwe 2006, Osuji, 2011).

Iwuoha et al., (2015) investigated the total potency equivalent concentration of cPAHs in the soil around sugi-bodo city and concluded that the soils are highly toxic and carcinogenic due to the presence and concentration of cPAHs.
The molecular weight and solubility of PAHs differs a lot and affect their characteristics, effects and partitioning in the environment and biological systems. The lower molecular weight PAHs, i.e. PAHs with two to three rings are reported to have significant acute toxicity to aquatic organisms while high molecular weight PAHs i.e. PAHs with four to seven rings are not markedly toxic to aquatic organisms, however some of these latter groups are known to be carcinogenic (Neff, 1979; Futoma et al., 1981).

The USEPA, (1993a) has identified seven PAHs as probable human carcinogen (Group B2) and mutagens. Benzo (a) pyrene $(\mathrm{BaP})$ fingered as a toxicological prototype of all carcinogenic PAHs (cPAHs), have been shown to cause cancer in laboratory animals after repeated dosing (Bradley et al., 1994).

The toxic effect of crude oil to micro and macro organism in soil, plants and vegetation have been reported (Abii and Nwosu, 2009; Henry and Heinke, 2005). Crude oil contains heavy metals such as; Fe, $\mathrm{Ni}, \mathrm{Cu}, \mathrm{Pb}, \mathrm{Zn}, \mathrm{V}$ etc. which could pose serious health risk if their heavy metal levels are substantially high and above baseline compliance 
limit for their discharge into the environment. Heavy metal toxicity in animals and humans could trigger a lot of degenerative diseases such as impairment of nervous functions, liver, lungs, and disruption of the endocrine, cardiovascular and gastrointestinal systems (Jang, 2011).

This paper is aimed at ascertaining the levels of PAHs and cPAHs in crude oil samples from Gokana area and using the data to determine the toxic potentials of the cPAHs in the crude oil sample. The article will as well report the levels of heavy metals in the crude oil and establish its potential toxicity risk to the people it is exposed to.

\section{MATERIALS AND METHODS}

Sample collection: The crude oil samples were collected from a well-known leaking petroleum pipelines in Gokana area of Rivers state with the assistance of the indigenes. The geographical coordinates of Gokana approximately falls within latitude $6^{0} 73^{\prime} \mathrm{N}$ and longitude $5^{0} 33^{\prime} \mathrm{E}$. The crude oil samples were collected with glass vials with Teflon caps and stored in the refrigerator at a temperature of less than $4^{\circ} \mathrm{C}$ before being taking to the Jawura laboratories, Port Harcourt for various analyses,

Sample preparation for Heavy Metal analysis: About ten milliliter of the crude oil sample was ashed in a furnace at about $400^{\circ} \mathrm{C}$ in a crucible. The ashed product was allowed to cool in a desiccator. After cooling, it was weighed and later digested with $10 \mathrm{ml}$ Nitric acid $\left(\mathrm{HNO}_{3}\right)$ in a fume chamber. Whatman number 44 filter paper was used to filter the digest into a $50 \mathrm{ml}$ standard flask that was initially washed and rinsed with acid. The $50 \mathrm{ml}$ mark was made up. A blank was prepared using $5 \mathrm{ml} \mathrm{HNO}_{3}$ acid. The heavy Metals ( $\mathrm{Ni}, \mathrm{Fe}, \mathrm{Cr}, \mathrm{Cd}, \mathrm{Cu}, \mathrm{Pb}$ and $\mathrm{Zn}$ ) were then determined using a flame atomic absorption spectrophotometer Agilent 55B AAS model with the respective hollow cathode lamp and at their resonance line of the Heavy metal. Metal concentration in $\mathrm{mg} / \mathrm{l}$ and $\mathrm{mg} / \mathrm{kg}$ were later computed accordingly.

Sample preparation and analysis for Polycyclic Aromatic Hydrocarbons

The crude oil was fractionated into saturated hydrocarbon and polycyclic aromatic hydrocarbons in a column chromatography. The polypropylene column was prepared by plugging a glass wool at the base of the column which support the baked $10 \mathrm{~g}$ silica gel packed in the column that serves as the stationary phase. The column was filled with the prepared eluent and the crude oil sample introduced slowly. About $60 \mathrm{ml}$ of $\mathrm{n}$-hexane was used to elute the aliphatic saturated hydrocarbon and the eluent collected with a conical flask. About $40 \mathrm{ml}$ of dichloromethane (DCM) was used to elute the PAHs. The eluents were collected differently with another conical flask and Pre-concentrated using rotary evaporator at $60^{\circ} \mathrm{C}$ to $1.3 \mathrm{ml}$. The different fractions were later analyzed with GC-FID, Agilent 6890 model with Chemstation 32 software. (USEPA, 1997, Massachusetts, 1995)

\section{RESULT AND DISCUSSIONS}

Tables 1 and 2 represents results of heavy metal and PAHs concentration respectively in the crude oil samples. Table 1 shows the results of selected heavy metal in $\mathrm{mg} / \mathrm{l}$ and its value in $\mathrm{mg} / \mathrm{kg}$ as well as the effluent limits in $\mathrm{mg} / \mathrm{kg}$ and $\mathrm{mg} / \mathrm{l}$ as the case may be. This allows for easy correlation. With the exception of nickel and chromium other heavy metals did not exceed their effluents limits. The order of concentration of heavy metal in the crude oil sample is $\mathrm{Fe}>\mathrm{Ni}>\mathrm{Cr}>\mathrm{Cu}>\mathrm{Cd}=\mathrm{Pb}=\mathrm{Zn}$ with concentrations in $\mathrm{mg} / \mathrm{kg}$ of $662.12,177.27,41.67$, 25.76, 0.001, 0.001 and 0.001 respectively. Cadmium, lead and zinc were actually below the detection limit of the analytical instrument used.

Table 1. Concentration of heavy metals in $\mathrm{mg} / \mathrm{l}$ and $\mathrm{mg} / \mathrm{kg}$ as well as the effluent limit in the crude oil sample.

\begin{tabular}{lll}
\hline & $\begin{array}{l}\text { CONC. } \\
(\mathbf{M g} / \mathbf{K g})\end{array}$ & $\begin{array}{l}\text { DPR EFFLUENT } \\
\text { LIMIT }(\mathbf{M g} / \mathbf{K g})^{\mathbf{A}}\end{array}$ \\
\hline $\mathbf{N i}$ & 177.27 & 0.10 \\
$\mathbf{F e}$ & 662.12 & $1.0(\mathrm{Mg} / \mathrm{L})^{\mathrm{B}}$ \\
$\mathbf{C r}$ & 41.67 & 0.03 \\
$\mathbf{C d}$ & 0.001 & 0.01 \\
$\mathbf{C u}$ & 25.76 & $1.5(\mathrm{Mg} / \mathrm{L})^{\mathrm{B}}$ \\
$\mathbf{P b}$ & 0.001 & 0.05 \\
$\mathbf{Z n}$ & 0.001 & $1.0(\mathrm{Mg} / \mathrm{L})^{\mathrm{B}}$ \\
\hline
\end{tabular}

Source; ${ }^{a}$ DPR, FME and WHO effluent limitation for in land areas (1991). DPR = Department of Petroleum Resources; FME = Federal ministry of Environment; WHO = World Health Organization. ${ }^{\mathrm{b}}$ DPR (2002).

${ }^{*}$ IWUOHA, $G ;{ }^{l}$ ORUBITE, $O ;{ }^{1}$ OKITE I 
The levels of nickel and chromium are 1772.70 and 1389 times respectively higher than the maximum effluent limits for inland areas as released by FME, the DPR and the WHO, however, the levels of zinc, copper, lead, cadmium and iron were lower than the maximum effluents limits for inland areas.

Zinc, copper, lead and cadmium were much lower than the effluent limits while iron was also much lower than the effluent limits. From the analysis above it is obvious that crude oil sample from spilled pipeline in Gokana area is highly toxic with respect to nickel and chromium; hence all efforts must be put in place to avoid human direct contact with it in order to avoid nickel and chromium toxicity.

Table 2. Concentration in ppm

$(\mathrm{mg} / \mathrm{l})$ of PAHs in the crude samples

\begin{tabular}{ll}
\hline $\begin{array}{l}\text { Amount in } \\
\text { mg/l }\end{array}$ & PAHs detected \\
\hline $\mathbf{1 0 5 . 9 7}$ & Naphthalene \\
$\mathbf{2 1 2 . 6 2}$ & Acenaphthalene \\
$\mathbf{2 6 1 7 . 8 8}$ & Acenaphthene \\
$\mathbf{2 8 4 5 . 9 8}$ & Fluorene \\
$\mathbf{3 2 5 4 . 5 1}$ & Phenanthrene \\
$\mathbf{-}$ & Anthracene \\
$\mathbf{4 0 2 1 . 2 2}$ & Fluoranthene \\
$\mathbf{5 9 4 . 7 5}$ & Pyrene \\
$\mathbf{4 6 . 9 7}$ & Benz (a) anthracene \\
$\mathbf{4 2 1 9 . 9 9}$ & Benzo (b) fluoranthene \\
$\mathbf{1 4 9 8 . 0 3}$ & Chrysene \\
$\mathbf{1 2 2 0 . 4 1}$ & Benzo (k) fluoranthene \\
$\mathbf{1 5 9 7 . 8 8}$ & Benzo (a) pyrene \\
$\mathbf{1 1 0 6 . 2 0}$ & Indeno (1,2,3-cd) pyrene \\
$\mathbf{8 3 1 . 8 3}$ & Dibenzo (a,h) anthracene \\
$\mathbf{8 6 5 . 0 7}$ & Benzo (g,h,i) Perylene \\
$\mathbf{2 5 0 3 9 . 3}$ & Total PAHs \\
\hline
\end{tabular}

The result of 16 PAHs shows that Anthracene was not dictated most likely because its value is below dictation limit of the G.C. used. Naphthalene, acenaphthalene, acenaphthene, fluorene, phenanthrene, fluoranthene, Pyrene, benzo (a) anthracene, benzo (a) fluoranthene, chrysene, benzo (k) fluoranthene, benzo (a) pyrene, indeno (1,2,3-cd) pyrene, dibenzo $(\mathrm{a}, \mathrm{h})$ anthracene and benzo $(\mathrm{g}, \mathrm{h}, \mathrm{i})$ perylene were detected at various concentrations.

The order of concentration of PAHs present in the crude oil sample in the decreasing order is as follows: Benzo (b) fluoranthene > fluoranthene > phenanthrene $>$ fluorene $>$ acenaphthene $>$ benzo (a) pyrene > chrysene > benzo (k) fluoranthene > indeno $(1,2,3-\mathrm{cd})$ perylene $>$ benzo $(\mathrm{g}, \mathrm{h}, \mathrm{i})>$ dibenzo (a,h) perylene > pyrene > acenaphthalene > naphthalene > benzo (a) anthracene with respective concentration in $\mathrm{mg} / \mathrm{l}$ as $4219.99>4021.22>$ $3254.98>2845.98>2617.88>1597.88>1498.03>$ $1220.41>1106.20>865.06>831,83>594.76>$ $212.62>105.97>46.97$.

All the cPAHs namely: benzo (a) pyrene, benzo (a) anthracene, benzo (b) fluoranthene, chrysene, benzo (k) fluoranthene, dibenzo $(\mathrm{a}, \mathrm{h})$ perylene and indeno (1,2,3-cd) pyrene were detected at various concentration in $\mathrm{mg} / \mathrm{l}$ as $1597.88,46.97,4219.99$, $1498.04,1220.41,831.82$ and 1106.20 respectively. The total concentration of cPAHs is $10,474.34 \mathrm{mg} / 1$ which represent $41.83 \%$ of the total PAHs (tPAHs) in the crude oil sample. The maximum acceptable limit for PAHs in crude oil sample is $0.0004 \mathrm{mg} / \mathrm{l}$ and $0.0007 \mathrm{mg} / 1$ as set by WHO and USEPA respectively. $\mathrm{BaP}$ which is the basis of estimating the carcinogenicity of cPAHs in an environmental mixture like crude oil sample has acceptable limit of $0.0004 \mathrm{mg} / \mathrm{l}$ and $0.0007 \mathrm{mg} / \mathrm{l}$ as set by WHO and USEPA respectively. Armed with this information and if we take upper value of $0.0007 \mathrm{mg} / \mathrm{l}$ as maximum permissible limit it means that benzo (a) pyrene is about 2282685.7 times higher (more toxic) than BaP standard, and represents about $6.38 \%$ of the total PAHs. Dibenzo $(\mathrm{a}, \mathrm{h})$ Perylene is about 1188328.6 times higher (more toxic) than $\mathrm{BaP}$ standard, and represents about $3.3 \%$ of the total PAHs. Benzo (b) fluoranthene is about 6028557.1 times higher (more toxic) than $\mathrm{BaP}$ standard, and represents about $16.85 \%$ of the total PAHs. Indeno (1, 2, 3-cd) pyrene is about 1580285.7 times higher (more toxic) than BaP standard, and represents about $4.4 \%$ of the total PAHs. Benzo $(\mathrm{k})$ fluoranthene is about 1743442.9 times higher (more toxic) than BaP standard, and represents about $4.87 \%$ of the total PAHs. Chrysene is about 2140042.9 times higher (more toxic) than BaP standard, and represents about $5.98 \%$ of the total PAHs. Benzo (a) anthracene is about 65957.14 times higher (more toxic) than $\mathrm{BaP}$ standard and represents about $0.19 \%$ of the total PAHs. The total PAHs (tPAHs) concentration in the crude oil sample $(25039.3 \mathrm{mg} / \mathrm{l})$ is high enough to trigger the various organs and physiological malfunctioning in the body.

Conclusion: All the cPAHs namely; Benzo (a) pyrene, benzo (a) anthracene, benzo (b) fluoranthene, chrysene, benzo $(\mathrm{k})$ fluoranthene, dibenzo $(\mathrm{a}, \mathrm{h})$ perylene and indeno (1,2,3-cd) pyrene were detected at various concentration in $\mathrm{mg} / \mathrm{l}$ as $1597.88,46.97$, $4219.99, \quad 1498.04,1220.41,831.82$ and 1106.20 respectively. Altogether the total concentration of

${ }^{*}$ IWUOHA, $\mathrm{G} ;{ }^{1}$ ORUBITE, O; ${ }^{1}$ OKITE I 
cPAHs is $10,474.34 \mathrm{mg} / \mathrm{l}$ which represent $41.83 \%$ of the total PAHs (tPAHs) in the crude oil sample. The respective cPAHs values exceeded the entire baseline compliance limits in thousands of folds and most have being the primary source of soil and water pollution in the area. The order of concentration (Fe $>\mathrm{Ni}>\mathrm{Cr}>\mathrm{Cu}>\mathrm{Cd}=\mathrm{Pb}=\mathrm{Zn}$ ) of heavy metal in the crude oil sample did not reflect their actual potential toxicity as only nickel and chromium exceeded their DPR maximum effluents limits.

Consideration and caution must be applied in exploration, exposure and distribution of crude oil through protected and well maintained pipelines to avoid the possible dangers of carcinogenic PAHs as well as nickel and chromium toxicity to the inhabitants of Gokana area.

Acknowledgements: The authors wish to express their gratitude to Mr. Justin of Jawura Environmental services Port Harcourt for his technical support during the time of analysis and all whose contributions led to improvement of the research.

\section{REFERENCES}

Abii, TA; Nwosu, PC (2009). The Effect of oil spillage on the soil of Eleme in Rivers State of the Niger Delta Area of Nigeria. Res. J. Environ. Sci., 3(3): 316-320.

Bradley, L.J.N., Magee, B.H., Allen, S.L. (1994). Background levels of PAHs and selected metals in New England Urban Soil. Journal of soil contamination, 3(4)

Department of Petroleum Resources (1991). Environmental guidelines and standards of the petroleum industry, Lagos. Pp. 35-76

Environmental guidelines and standards of the petroleum industry in Nigeria. Department of petroleum resources Lagos (1991). Pp. 32-56

Futoma, D.J., Smith, S.R., Smith, T.E. and Tanaka, J. (1981). Polycyclic Aromatic Hydrocarbons in water systems. CRC, Boca Press Raton, FL.

Henry, J G; Heinke, G W (2005). Environmental Science and Engineering, $2^{\text {nd }}$ ed. Prentice Hall, India, New Delhi 110001, 64-84.
Iwuoha, G.N., Nwigoo, J., Onojake, M.C (2015). Determination of Total Potency Equivalent Concentration (TPEC) of Carcinogenic Polycyclic Aromatic Hydrocarbons (cPAHs) In Soils of Bodo-City. J. Appl. Sci. Environ. Manage. Vol. 19(3), pp. 495-499.

Jang, D.H., and Hoffman, R.S. (2011). Heavy metal chelation in neurotoxic exposures. Neurol Clin. 29(3):607-22.

Method for the determination of extractable petroleum hydrocarbons (EPH) (1995). Massachusetts DEP, wall experiment station.

Neff, J. M. (1979). Polycyclic aromatic hydrocarbon in the aquatic environment; source, fates and biological effects. Applied science publishers, London.

Osuji, L.C (2011). Environmental perspectives; In Petroleum Chemistry and Toxicology. Uche's Business Services. Pp. 314.

Osuji, L.C and Uwakwe, A.A (2006). Petroleum industry effluents and other oxygen-demanding wastes in Niger Delta, Nigeria. Chemistry and Biodiversity vol. 3, pp. 705-717

Osuji, L.C., Ayolagha G.C., Obute, G.C., Ohabuike, H.C. (2007). Chemical and bio-geophysical impact of four- dimensional seismic exploration in sub-Sahara Africa, and Restoration of dyfunctionalised mangrove forest in the prospect areas. Chemistry and Biodiversity. Vol 4, pp. 2149-2165

Test methods for evaluating solid waste, physical and chemical methods SW-846, $3^{\text {rd }}$ edition (US Environmental Protection Agency, office of solid waste and Emergency Response Washington DC) June 1997

USEPA (1993a). Integrated risk information system (IRIS). Cincinnati, OH, environmental criteria and Assessment office, U.S. Environmental protection Agency 